\title{
Randomised Control Trial of 3 IU Intravenous Oxytocin Bolus With 7 IU Oxytocin Infusion Versus 10 IU Intramuscular Oxytocin in the Third Stage of Labour in the Prevention of Postpartum Hemorrhage
}

\author{
Aruna M Biradar $^{1}{ }^{\circledR}$, Rajasri G Yaliwal $^{1+}{ }^{\circledR}$, Shreedevi S Kori ${ }^{\circledR}$, Sangamesh S Mathapati ${ }^{\circledR}$, Shobha $S$ \\ Shiragur $^{1}{ }^{\circledR}$, Subhashchandra R Mudanur ${ }^{1}$
}

\begin{abstract}
Objectives: Intravenous (IV) oxytocin during vaginal delivery has been rarely used since an intramuscular (IM) route or IV infusion have been preferred in this regard. The trial aimed to compare the low-dose IV bolus 3 IU of oxytocin, along with 7 IU oxytocin infusion with $10 \mathrm{IU}$ oxytocin infusion in cesarean section.

Materials and Methods: A parallel control randomized study was conducted on a total of 320 consenting term pregnant women based on the inclusion criteria. The participants were randomized into either 3 IU IV bolus and 7 IU infusion of oxytocin or 10 IU of IM oxytocin following vaginal delivery. The difference in pre- and post-delivery hemoglobin $(\mathrm{Hb})$ levels, tone of the uterus, hemodynamic changes, adverse effects of the drug, and the need for additional uterotonics and blood transfusions were assessed based on the aim of the study.

Results: Based on the results, more women with severe blood loss were found in the IM oxytocin group in comparison to the IV bolus with infusion group following vaginal delivery. In addition, more women had a drop in the $\mathrm{Hb}$ of $3 \mathrm{gm} / \mathrm{dL}$ in the IM oxytocin group compared to the IV bolus-infusion group $(11 \%$ vs. $4 \%$, odds ratio $=0.768, P=0.469)$ although there was no statistical significance in this respect. The tone of the uterus was firmer in the IV bolus with infusion group at 3 and 5 minutes. Eventually, the difference in hemodynamic changes, side effects, and the need for additional uterotonics or blood transfusions was not significant.

Conclusions: In general, an IV bolus of 3 IU with a 7 IU infusion of oxytocin is as safe as and more effective than the IM injection of $10 \mathrm{IU}$ of oxytocin at the time of vaginal delivery for the prevention of postpartum hemorrhage.

Keywords: Oxytocin, Intravenous bolus, Intramuscular, Blood loss, Hemodynamics, Postpartum hemorrhage
\end{abstract}

\section{Introduction}

Postpartum hemorrhage is a major cause of maternal death across the world (1). The diagnosis of the dramatic event of postpartum hemorrhage (PPH) requires keen clinical acumen and swift treatment. The administration of prophylactic uterotonics immediately prior to or after the placental delivery or within 1 minute of birth can reduce blood loss, thereby decreasing maternal morbidity and mortality (2).

In this regard, various uterotonic agents have been used, including oxytocin, methyl ergometrine, misoprostol, and carbetocin. Oxytocin is the most effective uterotonic agent. The action of oxytocin depends on the number of myometrial receptors. The receptors increase as the pregnancy advances and are maximum at labor while they decrease sharply in advanced labor and the postpartum period. The receptors are minimal in number in the postpartum period, and hence the uterus becomes refractory to the action of oxytocin (3).

The best route and the dose of oxytocin is debatable.
The action of oxytocin by the intravenous (IV) route is almost immediate, however, the onset of action by the intramuscular (IM) route occurs in 3-7 minutes, and the preferred route of the prophylactic of oxytocin after vaginal delivery has traditionally been IM or IV infusions with a dose of 10 IU oxytocin (2).

The IV route is preferred during cesarean delivery. The IV bolus dose of oxytocin is quicker in action in comparison to the IM route. The applied dose of IV bolus oxytocin in cesarean section (C-section) has been variable, including 10, 5, 3, 2, and 1 IU of IV oxytocin bolus (4-8).

As the action of the IV bolus route of oxytocin is faster compared to the IM oxytocin, this study evaluated this route in patients delivering vaginally. In other words, the study aimed to determine the efficacy and safety of 3 IU IV oxytocin bolus, along with 10 IU IV oxytocin infusion in comparison to the standard practice of $10 \mathrm{IU}$ IM oxytocin after the delivery of the baby in preventing excessive bleeding. 
Key Messages

- Intravenous oxytocin in the dose of 3IU along with 7 IU infusion is as safe as and more effective than IM oxytocin when used post vaginal delivery.

- Concerns of hemodynamic instability after the administration of intravenous bolus oxytocin were not experienced in this study.

\section{Materials and Methods}

A parallel control randomized study was performed on 320 consenting women from 25th February to 25th May, 2020.

The present study included 320 pregnant women of term gestation visiting the Department of Obstetrics and Gynecology, Shri B.M. Patil Medical College Hospital and Research Center, Vijayapura . Written informed consent was obtained from all participants. Complete history and clinical findings were recorded in the prescribed format. In addition, the complete blood count was done for all patients on admission to the labor ward. The test was repeated after 48 hours of delivery. Participants were assigned to randomized groups according to a computergenerated randomization chart obtained from the web site of www.Randomization.com.

The study comprised of two groups (groups I and II). Group I $(n=160)$ received 3 IU IV oxytocin bolus with 7 IU oxytocin in IV infusion. Group II $(n=160)$ received 10 IU IM oxytocin.

Group I: 3 IU of oxytocin was diluted and administered intravenously over 1 minute. The drug was given at the time of delivery of the anterior shoulder of the baby. It should be noted that $1 \mathrm{~mL}$ oxytocin equals $5 \mathrm{IU}$. This was diluted in $4 \mathrm{~mL}$ of $0.9 \%$ normal saline, making it $1 \mathrm{I}$ $\mathrm{U}$ per $\mathrm{mL}$, and $3 \mathrm{~mL}$ was given bolus over 1 minute. The remaining $2 \mathrm{~mL}$ was given in IV infusion, along with another 5 IU of oxytocin making it 7 IU. The IV fluid was either Ringer's Lactate or $0.9 \%$ normal saline.

Group II: 10 IU IM oxytocin was given to the mother during the delivery of the anterior shoulder of the baby. Two ampoules of 5 IU of oxytocin were loaded in a single syringe and administered in the deltoid region.

The participants who were augmented with oxytocin during the first stage of labor were not excluded as the active management of the first stage of labor was followed in the institution.

The primary outcome was to assess the blood loss by calculating the difference in the pre- and post-delivery hemoglobin $(\mathrm{Hb})$ levels. The Hb levels were estimated as part of the complete blood count. The first pre-delivery complete blood count and post-delivery complete blood count were conducted 48 hours after the delivery.

The secondary measured outcomes were changes in the heart rate and systolic and diastolic blood pressure (BP), the tone of the uterus, the need for extra uterotonics and blood transfusion, and the side effects of the drugs, including nausea, vomiting, and the like.

The tone of the uterus was assessed on a 5-point scale. The uterine tone was assigned as 1 if atonic, 2 if there were partial, inadequate uterine contractions, 3 if there were adequate contractions, 4 if the uterus was well contracted, and 5 if the uterus was very well contracted.

Source of Data

Pregnant women admitted to the labor ward of the Department of Obstetrics and Gynecology in BLDE (Deemed to be University) Shri B.M. Patil Medical College, Hospital and Research Centre, Vijayapura, Karnataka, India were screened for participation in the study.

\section{Inclusion Criteria}

Women with a singleton pregnancy with the gestation age of 37-42 weeks who delivered vaginally.

\section{Exclusion Criteria}

Pregnant women with a previous history of uterine surgery (e.g., C-section, myomectomy, and the like) severe anemia, coagulopathies, associated cardiac, hepatic, renal diseases, and known conditions predisposing to atonic $\mathrm{PPH}$ such as hydramnios, multiple gestations, prolonged labor, severe pre-eclampsia and eclampsia. On the other hand, patients undergoing vacuum or forceps delivery or those who had cervical lacerations were excluded from the study.

\section{Sample Size Calculation}

Based on the study by Charles, Anger, Dabash et al (9), 320 (160 per group) pregnant women delivering vaginally are required to have a $90 \%$ chance of detecting, as significant at the $5 \%$ level, a decrease in the mean blood loss $(\mathrm{mL})$ from $180 \pm 100$ in group I to $214 \pm 100$ in group II. The calculation was based on the following formula:

$n=f(\alpha / 2, \beta) \times 2 \times \sigma 2 /(\mu 1-\mu 2) 2$

where $\mu 1$ and $\mu 2$ are the mean outcomes in the study groups, respectively, and $\sigma$ denotes the standard deviation.

\section{Data Analysis}

The statistical analysis of all characteristics is summarized descriptively. The summary statistics of $\mathrm{N}$, mean, standard deviation (SD) will be used for continuous variables. Regarding categorical data, the number and percentage are applied in data summaries. Further, data are analyzed by the Chi-square test for association, comparison of means using a $t$ test, ANOVA, and diagrammatic presentation. T-test/Z-test is used to know the efficacy of each method and the chi-square test is employed to compare the efficacy between the groups.

\section{Results}

During the study period (from $25^{\text {th }}$ February to $25^{\text {th }}$ May 
2020), a total of 1481 women delivered, of which 920 cases underwent C-section and 561 delivered vaginally. Of women who delivered vaginally, 506, 21, and 34 cases were term deliveries, vaginal birth after caesarean, and preterm deliveries, respectively. Of 506 women who delivered at term, 350 women met the inclusion criteria. Out of these 350 pregnant women, 320 gave their consent by signing an informed and written consent form and were included in the study.

Based on the results, there was no statistical difference regarding the age of the participants of groups I and II (23.61 vs. 23.87, $P=0.482$ ) (Table 1$)$. The weight of the participants in both groups was matched (60.31 vs. 61.31, $P=0.74)$, and the number of primigravidae and multigravida were equally matched in both groups (Table 2 ). The difference in pre- and post-delivery $\mathrm{Hb}$ values was calculated as well. In $90.6 \%$ and $88.1 \%$ of the women of groups I and II, the difference in the pre- and post-delivery $\mathrm{Hb}$ was less than $3 \mathrm{~g} / \mathrm{dL}$. A difference in the $\mathrm{Hb}$ values of more than $3 \mathrm{~g} / \mathrm{dL}$ was observed in $9.4 \%$ and $11.9 \%$ of the participants of groups I and II, respectively. There was an increased risk of excessive blood loss in group II in comparison to group I (OR 0.768, 95\% CI 0.375-1.57) (Table 3). Although the difference was not statistically significant, women in group II lost more blood. The number of the given episiotomies, incurred cervical lacerations, and observed perineal tears were similar in both groups. Three patients in group II and three patients in group I required additional uterotonics and styptics, respectively. There was only one blood transfusion in group II.

The majority of participants of group I reached grade 5 of the tone of the uterus at 3,5, and $10(P$ value at 3 minutes $=0.025, P$ value at 5 minutes $=0.043)$ minutes, implying that the IV bolus oxytocin, along with the infusion acted faster on the uterus (Figure 1).

No statistically significant differences were found in the heart rate, systolic BP, and diastolic BP before the intervention and at 5, 10, and 60 minutes in both groups (Figure 2).

\section{Discussion}

The study aimed at comparing the efficacy of bolus oxytocin with IM oxytocin regarding preventing excessive bleeding in women delivering vaginally. The study included 320 women who were randomized into two groups each including 160 women. Women in groups I and II were matched equally in terms of age, parity, and weight. Our results demonstrated that there was no difference in the two groups as the Hb drop was less than $3 \mathrm{gm} / \mathrm{dL}$. However, the chance of bleeding was more in group II as compared to group I if the drop in $\mathrm{Hb}$ was more than $3 \mathrm{~g} / \mathrm{dL}(\mathrm{OR}=0.768, P=0.469,95 \% \mathrm{CI}: 0.375$ 1.57). In a study conducted in the Republic of Ireland (8),

Table 1. Association of Age and Weight With Groups I and II

\begin{tabular}{|c|c|c|c|c|c|c|c|}
\hline \multirow{3}{*}{$\begin{array}{l}\text { Parameters } \\
\text { Age (years) }\end{array}$} & \multicolumn{2}{|c|}{ Group I } & \multicolumn{2}{|c|}{ Group II } & \multirow{2}{*}{$P$ Value } & \multirow{2}{*}{\multicolumn{2}{|c|}{$95 \% \mathrm{Cl}$ of Difference }} \\
\hline & \multirow{2}{*}{$\begin{array}{l}\text { Mean } \pm \text { SD } \\
23.61 \pm 3.33\end{array}$} & \multirow{2}{*}{$\begin{array}{c}\text { SE } \\
0.26\end{array}$} & \multirow{2}{*}{$\begin{array}{l}\text { Mean } \pm \text { SD } \\
23.87 \pm 3.35\end{array}$} & \multirow{2}{*}{$\begin{array}{c}\text { SE } \\
0.26\end{array}$} & & & \\
\hline & & & & & 0.482 & -1.00 & 0.47 \\
\hline Weight (kg) & $60.31 \pm 8.19$ & 0.65 & $61.31 \pm 9.41$ & 0.74 & 0.313 & -2.94 & 0.95 \\
\hline
\end{tabular}

Note. SD: Standard deviation; Cl: Confidence interval; SE: standard of error.

Table 2. Comparison of Parity, Hb Percentage, Traumatic Features, Additional Applied Drugs, and the Required Blood Transfusion Between the Two Groups

\begin{tabular}{|c|c|c|c|c|c|c|}
\hline \multirow{2}{*}{ Parameters } & \multicolumn{2}{|c|}{ Group I } & \multicolumn{2}{|c|}{ Group II } & \multirow{2}{*}{ Chi-square } & \multirow{2}{*}{$P$ Value } \\
\hline & No. & $\%$ & No. & $\%$ & & \\
\hline \multicolumn{7}{|l|}{ Gravida } \\
\hline Primigravida & 62 & $38.8 \%$ & 54 & $33.8 \%$ & \multirow{2}{*}{0.865} & \multirow{2}{*}{0.352} \\
\hline Multigravida & 98 & $61.3 \%$ & 106 & $66.3 \%$ & & \\
\hline \multicolumn{7}{|c|}{ Changes in pre- and post-delivery $\mathrm{Hb}(\mathrm{g} / \mathrm{dL})$} \\
\hline$<3$ & 145 & $90.6 \%$ & 141 & $88.1 \%$ & \multirow{2}{*}{0.527} & \multirow{2}{*}{0.468} \\
\hline$>3$ & 15 & $9.4 \%$ & 19 & $11.9 \%$ & & \\
\hline Episiotomy & 99 & $61.9 \%$ & 95 & $59.4 \%$ & 0.209 & 0.647 \\
\hline Cervical lacerations & 3 & $1.9 \%$ & 3 & $1.9 \%$ & - & - \\
\hline Perineal tears & 6 & $3.8 \%$ & 2 & $1.3 \%$ & 2.051 & 0.152 \\
\hline Tachysystole & 0 & $0.0 \%$ & 0 & $0.0 \%$ & - & - \\
\hline Additional used uterotonics & 0 & $0.0 \%$ & 3 & $1.9 \%$ & 4.013 & 0.134 \\
\hline Applied styptics & 3 & $1.9 \%$ & 1 & $0.6 \%$ & 1.01 & 0.314 \\
\hline Any blood transfusion & 0 & $0.0 \%$ & 1 & $0.6 \%$ & 2.013 & 0.366 \\
\hline Total & 160 & $100.0 \%$ & 160 & $100.0 \%$ & & \\
\hline
\end{tabular}

Note. Hb: hemoglobin. 
Table 3. OR of Pre- and Post-delivery Hb g/dL in Group II Compared to Group I

\begin{tabular}{lcccc}
\hline Hb Changes $(\mathbf{g} / \mathbf{d L})$ & OR & P Value & \multicolumn{2}{c}{$\mathbf{9 5} \%$ CI OR } \\
\hline$<3$ & 1.303 & 0.469 & 0.637 & 2.664 \\
$>3$ & 0.768 & 0.469 & 0.375 & 1.57 \\
\hline
\end{tabular}

Note. OR: Odds ratio; Hb: Hemoglobin; Cl: Confidence interval.

10 IU IV oxytocin was administered over 1 minute and compared to $10 \mathrm{IU}$ of the IM administration of oxytocin after vaginal delivery. Based on the results, although no difference in the prevention of PPH was observed in mild $\mathrm{PPH}$, it was evident in severe $\mathrm{PPH}$, and admission to high dependency units was lesser in the IV bolus group in comparison with the IM group (9). In another largescale study conducted in Egypt, 10 IU IV bolus oxytocin was found to be superior to 10 IU IM oxytocin in vaginal delivery (9). However, the other systematic review could not establish whether the IV or IM route was superior and concluded that larger randomized control trials were required in this regard (10).

The hemodynamics of the patients were stable in both groups and no difference was found between the groups in this regard. The results represented that IV bolus oxytocin in the dose of 3 IU was as safe as IM oxytocin, which is in line with the findings of other recent studies on IV bolus oxytocin in post-delivery cases $(8,9)$. It also shows that the older concept that IV oxytocin is unsafe and may cause hemodynamic instability does not hold well in cases of vaginal delivery (9). Similar studies conducted administrating IV bolus oxytocin showed no side effects or adverse outcomes in comparison to IV oxytocin infusion $(11,12)$. Some studies reported that there were stronger uterine contractions followed by IV bolus oxytocin, but this route was not frequently used due to an immediate decrease in the BP, even though this side effect of IV bolus oxytocin was frequently observed in patients who underwent caesarean section under general anesthesia $(5,13)$. Various studies showed that IV bolus oxytocin, when given in large doses, has adverse effects such as a decrease in BP, headache, nausea, vomiting, and even myocardial infarction in extreme cases. However, in our study, a smaller dose of IV oxytocin when given in bolus demonstrated no serious hemodynamic changes as seen in other studies $(5,14,15)$. According to a Syntocinon Infusion trial, hemodynamic changes occurred mainly due to the regional anesthesia during caesarean section instead of IV bolus oxytocin (16).

In a study conducted on women undergoing C-section, the IV bolus of either 2 IU or 5 IU, along with the infusion of $0.25 \mathrm{IU} / \mathrm{mL}$ was compared to the IV infusion of oxytocin of $0.5 \mathrm{IU} / \mathrm{mL}$. Based on the results, there were marked hemodynamic changes in heart rate and mean arterial pressure in the bolus-infusion groups compared to the only infusion group. However, changes were less in the $2 \mathrm{IU}$ bolus group. The uterine tone increased in the bolus-infusion group in comparison to the infusion

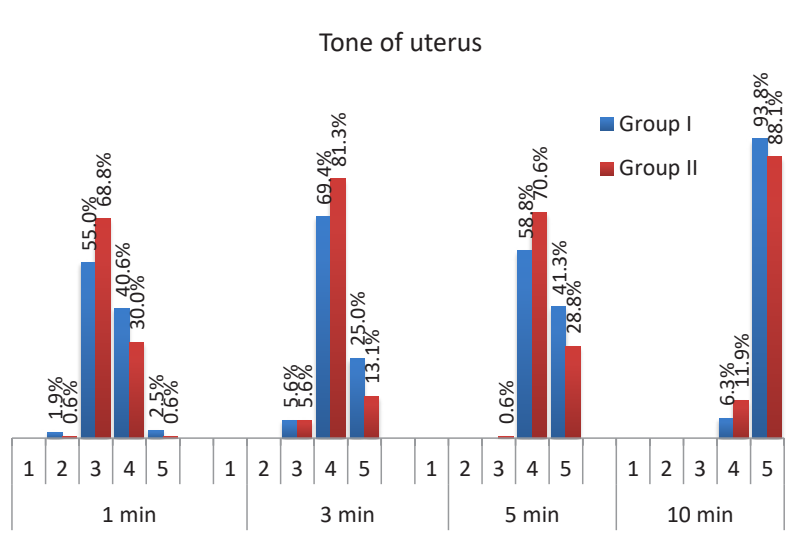

Figure 1. Comparison of Tone of Uterus at 1, 3, 5, and 10 Minute(s) Between the Two Groups.

Haemodynamic Parameters

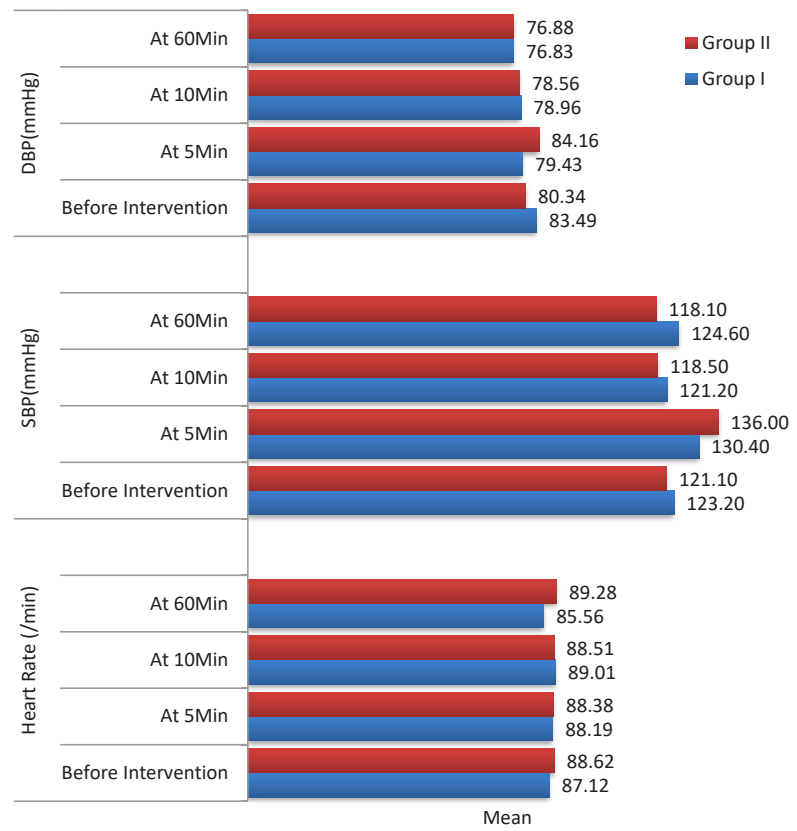

Figure 2. Comparison of Hemodynamic Parameters Between the Two Groups. Note. SBP: Systolic blood pressure; DBP: Diastolic blood pressure.

group (4). In the present study, the uterine tone was assessed to be firmer in group I than in group II at 3 and 5 minutes. This would hypothetically reduce the need for additional uterotonics. However, this did not reflect in the results thus further large-scale research would be needed in this respect. Another study attempted to calculate the least bolus dose of oxytocin that could be required in scheduled $\mathrm{C}$-sections and for $\mathrm{C}$-sections done for difficult labor. It was recommended that the 1 IU of oxytocin for elective C-section and 1-1.5 IU bolus oxytocin for cesareans done for labor progress should be administered in this regard (17). The World Health Organization advises 10 IU oxytocin either IV or IM for the prevention of postpartum hemorrhage (18). Most of the recommendations for postpartum hemorrhage do 
not differentiate between vaginal delivery and C-section. Similarly, there are no guidelines to suggest different doses for women undergoing an elective C-section and women who are in labor. IV bolus oxytocin has been studied in various doses of 2, 3, 5, and $10 \mathrm{IU}$ during C-section (4-7). Studies on the bolus-infusion of oxytocin during vaginal delivery are necessary. This route could be a preferred route in cases where IM injections are contraindicated like thrombocytopenia.

\section{Limitations of the Study}

The study did not record the visible blood loss at labor and did not include the fetal outcome as the drug was administered after the delivery of the fetus.

\section{Conclusions}

Overall, 3 IU IV oxytocin bolus, along with 7 IU oxytocin infusion reduced the occurrence of severe postpartum hemorrhage in comparison to 10 IU IM oxytocin without causing any significant hemodynamic changes. Finally, the uterine tone increased faster in women who were administered IV bolus oxytocin and infusion as compared to IM oxytocin.

\section{Authors' Contribution}

$\mathrm{AMB}$ and RGY conceptualized, designed, executed the study and prepared the manuscript. SSK, SSM and SSS executed the study. SRM overviewed the study and managed the logistics of the study.

\section{Conflict of Interests}

Authors declare that they have no conflict of interests.

\section{Ethical Issues}

The study was approved by the Institutional Ethical Committee of BLDE University (No. BLDE(DU)/IEC/355-/2019-20) and registered in the Clinical Trials of India (Ref No. CTRI/2020/02/023521).

\section{Financial Support}

The authors received no institutional or external funding during the research.

\section{References}

1. Say L, Chou D, Gemmill A, et al. Global causes of maternal death: a WHO systematic analysis. Lancet Glob Health. 2014;2(6):e323-333. doi:10.1016/s2214-109x(14)70227-x

2. World Health Organization (WHO). WHO Recommendations: Uterotonics for the Prevention of Postpartum Haemorrhage. Geneva: WHO; 2018.

3. Yulia A, Johnson MR. Myometrial oxytocin receptor expression and intracellular pathways. Minerva Ginecol. 2014;66(3):267280.

4. Kim TS, Bae JS, Park JM, Kang SK. Hemodynamic effects of continuous intravenous injection and bolus plus continuous intravenous injection of oxytocin in cesarean section. Korean J Anesthesiol. 2011;61(6):482-487. doi:10.4097/ kjae.2011.61.6.482
5. Thomas JS, Koh SH, Cooper GM. Haemodynamic effects of oxytocin given as i.v. bolus or infusion on women undergoing caesarean section. $\mathrm{Br}$ J Anaesth. 2007;98(1):116-119. doi:10.1093/bja/ael302

6. Tandon R, Khan TA, Mehrotra S. Oxytocin given as IV bolus versus IV infusion in women undergoing caesarean section- a randomised, controlled, double-blind study. J Evol Med Dent Sci. 2018;7(11):1423-1425. doi:10.14260/jemds/2018/323

7. Mathe P, Kale S, Batra A, Batra A, Aggrawal S, Nagarajappa A. Intravenous oxytocin bolus and infusion versus infusion alone on the blood loss during caesarean section. Int J Reprod Contracept Obstet Gynecol. 2019;8(12):4824-4828. doi:10.18203/2320-1770.ijrcog20195328

8. Adnan N, Conlan-Trant R, McCormick C, Boland F, Murphy DJ. Intramuscular versus intravenous oxytocin to prevent postpartum haemorrhage at vaginal delivery: randomised controlled trial. BMJ. 2018;362:k3546. doi:10.1136/bmj. k3546

9. Charles D, Anger H, Dabash R, et al. Intramuscular injection, intravenous infusion, and intravenous bolus of oxytocin in the third stage of labor for prevention of postpartum hemorrhage: a three-arm randomized control trial. BMC Pregnancy Childbirth. 2019;19(1):38. doi:10.1186/s12884-019-2181-2

10. Beiranvand S, Karimi A, Vahabi S, Amin-Bidokhti A. Comparison of the mean minimum dose of bolus oxytocin for proper uterine contraction during cesarean section. Curr Clin Pharmacol. 2019;14(3):208-213. doi:10.2174/15748847146 66190524100214

11. Löytved-Hardegg JJ, Brunner M, Ries JJ, et al. Replacement of oxytocin bolus administration by infusion: influences on postpartum outcome. Arch Gynecol Obstet. 2016;293(6):12191225. doi:10.1007/s00404-015-3916-6

12. Davies GA, Tessier JL, Woodman MC, Lipson A, Hahn PM. Maternal hemodynamics after oxytocin bolus compared with infusion in the third stage of labor: a randomized controlled trial. Obstet Gynecol. 2005;105(2):294-299. doi:10.1097/01. AOG.0000148264.20909.bb

13. Hendricks $\mathrm{CH}$, Brenner WE. Cardiovascular effects of oxytocic drugs used post partum. Am J Obstet Gynecol. 1970;108(5):751-760. doi:10.1016/0002-9378(70)90542-9

14. Pinder AJ, Dresner M, Calow C, Shorten GD, O'Riordan J, Johnson R. Haemodynamic changes caused by oxytocin during caesarean section under spinal anaesthesia. Int J Obstet Anesth. 2002;11(3):156-159. doi:10.1054/ijoa.2002.0970

15. Michelini LC, Marcelo MC, Amico J, Morris M. Oxytocinergic regulation of cardiovascular function: studies in oxytocin-deficient mice. Am J Physiol Heart Circ Physiol. 2003;284(6):H2269-2276. doi:10.1152/ajpheart.00774.2002

16. McLeod G, Munishankar B, MacGregor H, Murphy DJ. Maternal haemodynamics at elective caesarean section: a randomised comparison of oxytocin 5-unit bolus and placebo infusion with oxytocin 5-unit bolus and 30-unit infusion. Int J Obstet Anesth. 2010;19(2):155-160. doi:10.1016/j. ijoa.2009.08.005

17. Oladapo OT, Okusanya BO, Abalos E. Intramuscular versus intravenous prophylactic oxytocin for the third stage of labour. Cochrane Database Syst Rev. 2018;9(9):CD009332. doi:10.1002/14651858.CD009332.pub3

18. World Health Organization (WHO). WHO Handbook for Guideline Development. Geneva: WHO; 2012.

\footnotetext{
(C) 2021 The Author(s); This is an open-access article distributed under the terms of the Creative Commons Attribution License (http:// creativecommons.org/licenses/by/4.0), which permits unrestricted use, distribution, and reproduction in any medium, provided the original work is properly cited.
} 